\title{
Alloying Property of a Conductive Filler to Resolve the Re-melting Issue
}

\author{
Kaoru SUGIMOTO*,***, Tomohisa YAGI**, \\ Hideo HONMA ${ }^{* * *}$ and Mitsuhiro WATANABE***
}

(Received July 5, 2018)

\begin{abstract}
In the field of circuit boards, a paste technology making it possible to develop a new interconnection technology is highly requested. In this study, we worked on the realization of a new metal-bonding-type conductive paste supplementing the weakness of the conventional via-filling one. This conductive paste is a complete melting-point-changing-type paste in which large spherical copper $(\mathrm{Cu})$ powder (particle diameter of 25 to $50 \mu \mathrm{m}$ ) is used as a conductive filler and an alloy of tin (Sn) and bismuth (Bi) is coated on its surface. It distinguishes itself from the previous ones by the absence of metallic components since it is only composed of $\mathrm{Cu}$ coated with $\mathrm{Sn}$-Bi. This paste not only ensure a high connection reliability between multilayer circuit boards, but also does not re-melt after two or more unavoidable thermal exposures needed throughout the production process. In this paper, we evaluated the thermal properties of the $\mathrm{Cu}$ filler alloying used in this conductive paste. An observation of the alloying made of a $\mathrm{Cu}$ core coated with $\mathrm{Sn}$-Bi showed that its thermal property depended on the thickness of the layer. Provided this result, a Sn-Bi alloy which doesn't re-melt was found by analyzing the thermal properties of different thicknesses of the same alloy and observing the variation of the melting-point during the re-heating.
\end{abstract}

Key Words: Circuit Boards, Conductive Paste, Melting-point-changing, Cu Filler, Sn-Bi Alloying

\section{Introduction}

A variety of conductive pastes including nano-level fillers have been developed and placed on the market as bonding materials to substitute the solder paste indispensable during the electronic components assembly. ${ }^{1-14)}$ More than two decade ago, to answer the strong need for a technology ensuring interconnections between circuits boards, a conductive paste used as a via-filling material was developed and put to practical use. Conductive pastes are generally made of a mix of spherical filler of copper $(\mathrm{Cu})$ or silver $(\mathrm{Ag})$ of about 5 to $10 \mu \mathrm{m}$ diameter, fine particles of low melting point materials and adhesive resin. Until now, the filler contact density of a paste depended on the compression rate and the connection between the upper and lower pad was only maintained by the contact force once the curing is done. Applying it to a multilayer stack via circuit structure may jeopardize the circuit board performance since there is a high risk that, in the long-term, the electric resistance stability will be compromised by a high thermal cycle. For this reason, its application has been limited to approximately ten layers or less ${ }^{15)-18)}$, and the actual number of application to circuit boards and commercialization is very low. In order to overcome these limitations, a sintering type paste ${ }^{19-25)}$ has been developed and commercialized. However as the problem of preserving the connection strength with connection pads on a circuit board which requires a very complex control process and technology management has not been resolved, it application did not expand as expected.

Taking into account these problems, we worked on the realization of a new metal-bonding-type conductive paste supplementing the weaknesses of both the conventional pressure type or and sintering type pastes. The purpose is to realize interconnection between high-layer-count/thick circuit boards and at the same time, increasing the reliability and the thermal history resistance during the component mounting. This conductive paste is a complete melting-point-change-type paste in which large spherical $\mathrm{Cu}$ powder (particle diameter 25 to $50 \mu \mathrm{m}$ ) is used as a conductive filler and an alloy of $\mathrm{Sn}$ and $\mathrm{Bi}$ is coated on its surface. This paste characterize itself by the formation of a $\mathrm{Cu}-\mathrm{Sn}$ intermetallic compound (IMC) on the surface of the $\mathrm{Cu}$ filler entering in contact with the Sn-Bi coating layer. The $\mathrm{Cu}$ filler is the only metallic component in this composition.

In this paper, to be sure that the alloying would not re-melt after the first metal bonding, we evaluated the thermal properties

*富士通インターコネクトテクノロジーズ株式会社 ビジネス開発統括部（２ 211-8588 神奈川県川崎市中原区上小田中 4-1-1 (本 -1014) )

Fujitsu Interconnect Technologies Limited, Business Development Division

(1-1, Kamikodanaka 4-chome, Nakahara-ku, Kawasaki 211-8588, Japan (Company Mail No./Hon-1014))

**富士通クオリティ・ラボ株式会社（～674-8555 兵庫県明石市大久保町西脇 64 番地 富士通明石工場内）

Fujitsu Quality Laboratory Limited (64-Nishiwaki,Okubo-cho, Akashi-shi, Hyogo 674-8555, Japan (Fujitsu LTD, Akashi Office))

*** * 関東学院大学 大学院工学研究科 († 250-0042 神奈川県小田原市荻窪 1162-2)

Graduate School of Engineering, Kanto Gakuin University (1162-2, Ogikubo, Odawara-shi, Kanagawa 250-0042, Japan) 
of Sn-Bi coating layer to determine the optimal alloying conditions for the $\mathrm{Cu}$ filler.

The bonding state of $\mathrm{Cu}$ filler after curing was observed and the alloying state analyzed. The alloying layer made of $\mathrm{Cu}$ core coated with Sn-Bi was also observed to find any correlation between the thickness and the time of melting. Then, the variation of the melting point after re-heating was observed and evaluated to find the best Sn-Bi alloying layer coating thickness to avoid the re-melting.

\section{Experimental procedure}

\subsection{A paste composition}

This paste material is made of a spherical $\mathrm{Cu}$ powder used as a conductive filler and an epoxy type flux compound (Fujitsu Quality Laboratory Co., Ltd.) used as an adhesive resin. The spherical $\mathrm{Cu}$ particles compound ratio was set at 89 to $91 \mathrm{wt} \%$ and the diameter of the core at 25 to $50 \mu \mathrm{m}$. The surface of the plating was then coated by an alloy of Sn $42 \pm 10 \%$ and Bi $58 \pm$ $10 \%$. The thickness of the coating of $\mathrm{Sn}-\mathrm{Bi}$ on the $\mathrm{Cu}$ particle was about 1 to $5 \mu \mathrm{m}$ and the weight ratio $21 \% \mathrm{wt}$.

\subsection{Thermal property and alloying analysis of a paste}

\subsubsection{Heating measurement}

The experiment started by the analysis of the paste thermography with a differential scanning calorimetry (DSC). It was followed by the $\mathrm{Cu}$ particles cross section observation.

First, the variation of the dynamic DSC of the adhesive resin on its one was observed throughout the heating. Once the variation of the dynamic DSC observed, the same process was used for the conductive paste made of $\mathrm{Cu}$ particles coated with Sn-Bi mixed with the adhesive resin.

Once the paste cured, the cross section and the elemental mapping of the alloying the $\mathrm{Cu}$ particles coated with $\mathrm{Sn}-\mathrm{Bi}$ were analyzed.

Concerning the measuring equipment, a differential scanning calorimeter (Seiko Instruments DSC100), a metallurgical microscope for cross section observation (Olympus PMG3), a scanning electron microscope (Hitachi SEM-X650) and a FESEM (JEOL JED-2300) were used.

\subsubsection{Coating thickness measurement}

An experiment was conducted to find an appropriate thickness condition to prevent the coated $\mathrm{Sn}-\mathrm{Bi}$ from re-melting between the alloyed $\mathrm{Cu}$ particles. The $\mathrm{Sn}-\mathrm{Bi}$ alloying thickness around the $\mathrm{Cu}$ particle was set at 1 to $4 \mu \mathrm{m}$. It variation after two heating was observed with the dynamic DSC.

To find the most reliable paste thickness after two heating cycles, the most suitable Sn-Bi coating thickness found during the thickness measurement, a coating thicker than the first one, and as a reference, an ordinary solder paste were used for this experiment. The heating temperature for the paste was set at $15^{\circ} \mathrm{C} / \mathrm{min}$ from $180{ }^{\circ} \mathrm{C}$ to $250{ }^{\circ} \mathrm{C}$ as the bonding sheet doesn't stiff under $150{ }^{\circ} \mathrm{C}$. The heating temperature for the adhesive resin was set at $300{ }^{\circ} \mathrm{C}$.

A differential scanning calorimeter (Seiko Instruments DSC100) was used for this measurement.

\section{Results and discussion}

\subsection{DSC observation of conductive paste}

Fig. 1 shows the dynamic DSC results obtained after a continuous heating of the conductive paste. First, Fig. 1(a) shows the DSC curve of the adhesive resin by itself. In this case, due to the absence of due to the absence of metal components, the curing starts at $147.8^{\circ} \mathrm{C}$, peaks at around $232.4^{\circ} \mathrm{C}$, and is completed at $288.2^{\circ} \mathrm{C}$. Two relatively close endothermic peaks were observed at $70{ }^{\circ} \mathrm{C}$ and $110^{\circ} \mathrm{C}$. This thermal behavior is similar to the ordinary $\mathrm{Cu}$ particles with Ag plating. There is only a slight difference during the exothermic peak. Fig. 1(b) shows the DSC curve of a paste made of a mix of the adhesive resin and $\mathrm{Cu}$ particles with a Sn-Bi coating. Here, the curing of the adhesive resin starts at 113. $2^{\circ} \mathrm{C}$, the curing peak is obtained at $142.0^{\circ} \mathrm{C}$ and the final completion of curing is observed at $184.7^{\circ} \mathrm{C}$. There is a $90{ }^{\circ} \mathrm{C}$ difference between the two curing peaks in Fig. 1. It is believed that similarly to the experience on the influence of the SAC304

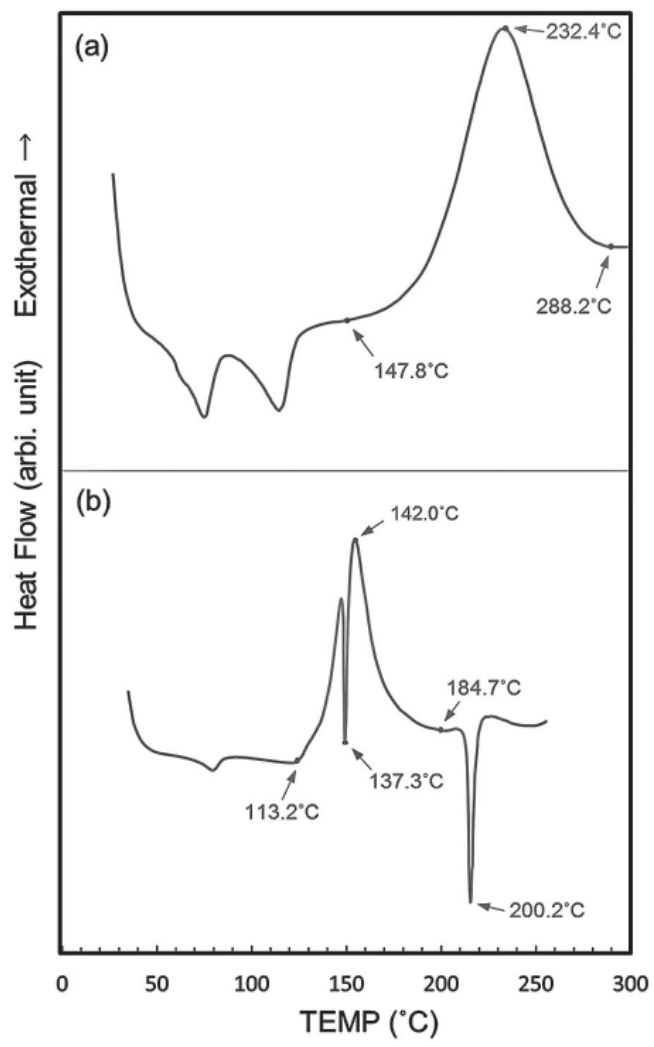

Fig. 1 Measurement result of dynamic DSC. (a) Case as heating part of the adhesive. (b) Case heating of $\mathrm{Cu}$ particles mixed paste. 
metallic particles on the flux, the presence of Sn-Bi speeds up the hardening reaction of the epoxy resin. ${ }^{26)}$

Furthermore, a strong endothermic peak is observed at $137.3{ }^{\circ} \mathrm{C}$ matching with the $\mathrm{Sn}-\mathrm{Bi}$ eutectic composition and an even stronger one is observed at $200.2^{\circ} \mathrm{C}$. This would indicate that the final reaction of $\mathrm{Cu}$-Sn alloying occurs here, and that the metal bonding between the $\mathrm{Cu}$ particles is completed. This can be attributed, with the backup of some studies on the properties of $\mathrm{Sn}-\mathrm{Bi}$ and $\mathrm{Cu}$ interface ${ }^{27), 28)}$, to some remaining $\mathrm{Sn}$ after the Sn-Bi eutectic.

\subsection{An analysis of the alloying state of the $\mathrm{Cu}$ particle}

Fig. 2 is a cross section of the $\mathrm{Cu}$ particles after the paste curing. The $\mathrm{Cu}$ particles aggregation between the upper and lower bonding pads and the contact condition of the Sn-Bi layer coating the $\mathrm{Cu}$ surface were observed. An elemental analysis was conducted to understand how the Sn-Bi alloy remains on the $\mathrm{Cu}$ surface. Fig. 3 shows the $\mathrm{Cu}$ particles elemental mapping results. Fig. 3(a) shows the whole image and Fig. 3(b) shows the

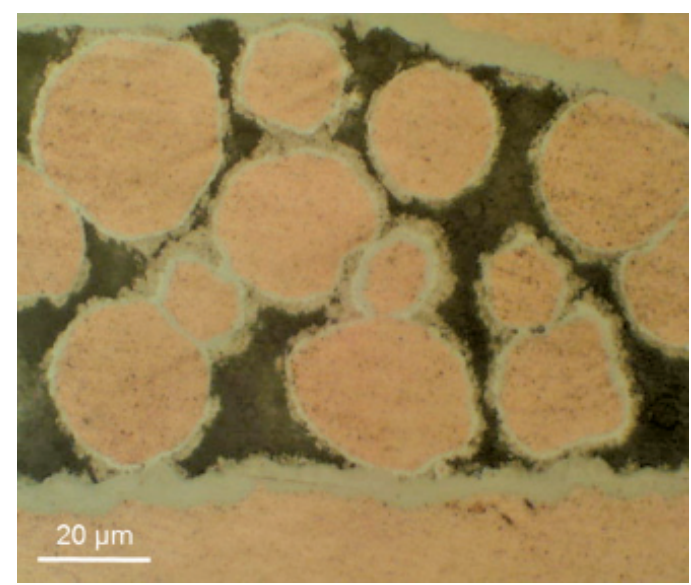

Fig. 2 Cross sectioning of $\mathrm{Cu}$ particles after paste curing.
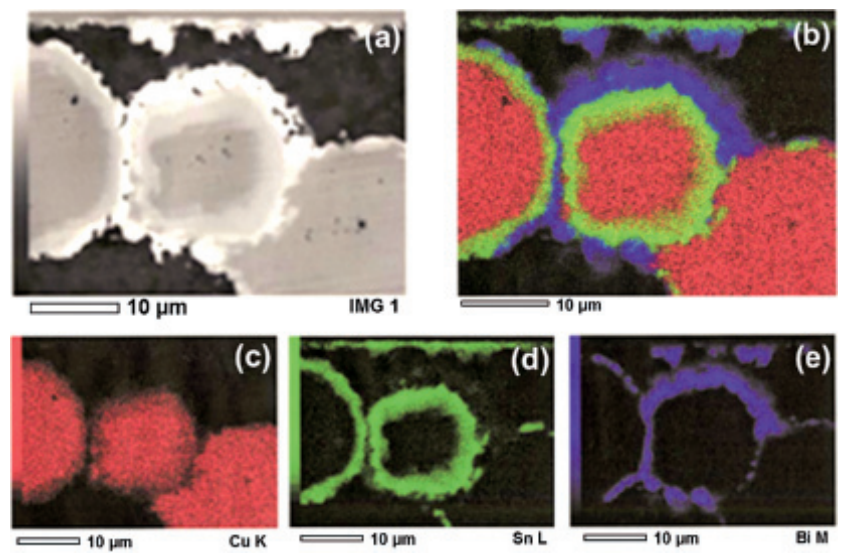

Fig. 3 Elemental mapping of $\mathrm{Cu}$ particles after paste curing. (a) Mono Image. (b) All elemental mapping, (c) Elemental mapping of Cu. (d) Elemental mapping of Sn. (e) Elemental mapping of Bi. total elemental mapping. Fig. 3(c), (d), (e) show the individual elemental mapping of respectively $\mathrm{Cu}, \mathrm{Sn}, \mathrm{Bi}$. These results demonstrate that much of the $\mathrm{Sn}-\mathrm{Bi}$ coating remains on the $\mathrm{Cu}$ core surface.

When the conductive paste is used as a conductive connection between printed circuit boards, it is common to use an epoxy type insulating resin such as prepreg as bonding sheet for the lamination. Therefore, the bonding sheet need to meet the alloying characteristics of the paste. In order to efficiently join the $\mathrm{Cu}$ particles, Sn-Bi alloy's melting point should be around the eutectic one and melt and harden in no time. The alloying of $\mathrm{Sn}-\mathrm{Bi}$ should be also achieved while keeping the melting condition of the bonding sheet. This characteristic is necessary to increase the contact area between the $\mathrm{Cu}$ particles when curing the pressurized bonding sheet and to perform an efficient metal bonding. This shows the importance to determine a Sn-Bi coating thickness able to complete the alloying in no time.

3.3 A condition of Sn-Bi coating thickness of $\mathrm{Cu}$ particle

The quality of the alloying made of $\mathrm{Cu}$ core coated with Sn$\mathrm{Bi}$ was investigated by variating the coating thickness and verifying if it melts during the second heating process. Fig. 4 shows the observing results of the dynamic DSC. Three different

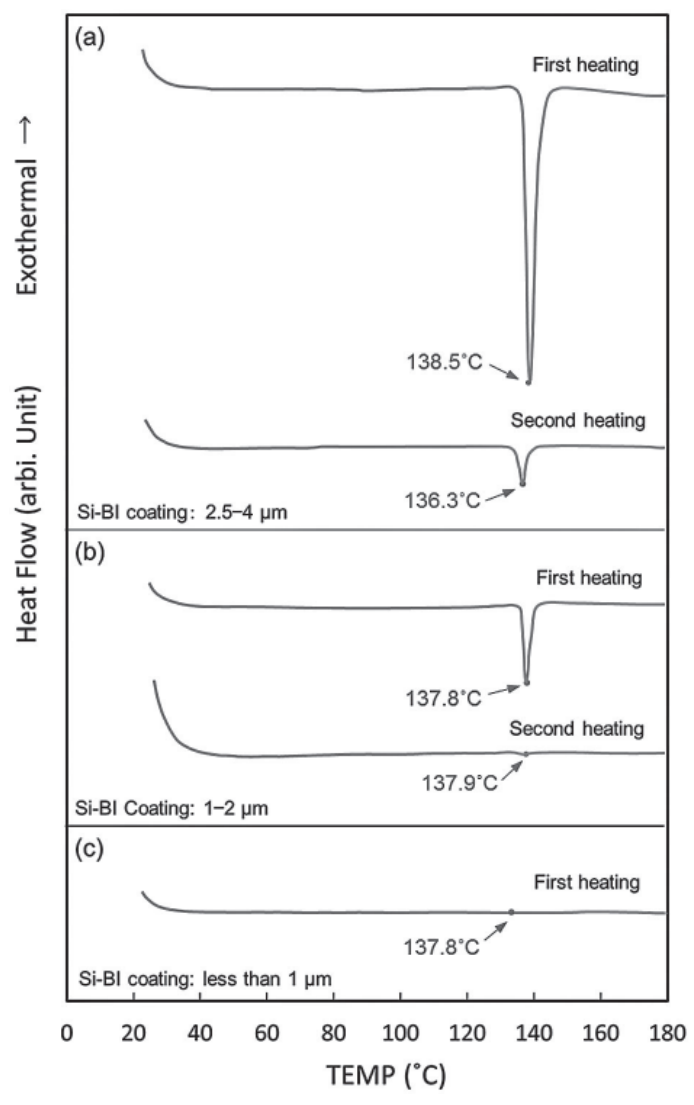

Fig. 4 Measurement result of dynamic DSC. (a) Case as heating of 2.5-4 $\mu \mathrm{m}$ Sn-Bi. (b) Case heating of 1-2 $\mu \mathrm{m}$ Sn-Bi. (c) Case as heating less than $1 \mu \mathrm{m}$ Sn-Bi. 
Sn-Bi coating thicknesses were selected for this experiment: 2.5 to $4 \mu \mathrm{m}, 1$ to $2 \mu \mathrm{m}$, and less than $1 \mu \mathrm{m}$. Fig. 4 (a) shows that on both first and second heating processes, an endothermic peak appeared first at $138.5^{\circ} \mathrm{C}$ and then at $136.3^{\circ} \mathrm{C}$. In Fig. 4 (b) a single endothermic peak of $137.8^{\circ} \mathrm{C}$ was observed at the first heating. Finally on Fig. 4 (c) no endothermic peaks were found. The two endothermic peaks observe in Fig. 4(a) and (b) shows an eutectic point fusion similar it shown in the phase diagram of $\mathrm{Sn}-\mathrm{Bi}^{27)}$ However, the absence of an endothermic peak in Fig. 4(c), could indicate an intermetallic compound (IMC) formation during the first heating cycle as the alloying layer of $\mathrm{Sn}-\mathrm{Bi}$ is extremely thin. Furthermore, due to the Bi tendency to deposit first, it is possible, that in the case of an extremely thin Sn-Bi plating process only $\mathrm{Bi}$ would remain. The $\mathrm{Cu}$ particle must go through at least two the thermal loads (without re-melting) and during the heating/curing process it must attain the melting point and alloy. These results shows that by keeping the Sn-Bi coating thickness to 1 to $2 \mu \mathrm{m}$, it will prevent the alloy from re-melting.

\subsection{Re-melting evaluation of a paste}

A dynamic DSC was conducted to analyze a paste with a $\mathrm{Cu}$ coated with the supposed most suitable coating thickness of SnBi.

Fig. 5 shows the cross section of different Sn-Bi coating thickness of $\mathrm{Cu}$ cores. The thickness of the Sn-Bi alloying coating thickness on the $\mathrm{Cu}$ core surface for respectively 5 $\mu \mathrm{m}, 2 \mu \mathrm{m}$ can be observed. Fig. 6 shows the dynamic DSC of two pastes with different coating thicknesses. The same method employed in section 3.3 was applied here to compare the endothermic peaks during the first and second heating. The results of an ordinary solder paste were used as a reference.

Fig. $6 \mathrm{I}$ shows the DSC curve of the paste with a $5 \mu \mathrm{m}$ coating thickness. During the first heating the curing started at $112.1{ }^{\circ} \mathrm{C}$ and the endothermic peak of Sn-Bi eutectic point appeared at $142.6{ }^{\circ} \mathrm{C}$. In the second heating, the endothermic peak of Sn-Bi appeared at $145.5^{\circ} \mathrm{C}$ and an endothermic peak indicating a remelting was found. The shift of the eutectic point to the first half of $140{ }^{\circ} \mathrm{C}$ could be explained by a several percentage margin error in the Sn-Bi alloy distribution.

On the other hand, Fig. 6 II shows the DSC curve of the paste with a 2 um coating thickness, the curing of the resin starts at $111.2^{\circ} \mathrm{C}$, and the endothermic peak of the Sn-Bi eutectic point is observed at $139.6{ }^{\circ} \mathrm{C}$. The absence of an endothermic peak during the second heating indicate that the Sn-Bi re-melting did not occur. Then, regarding the solder paste used as reference in the group $\mathbb{I I}$ of Fig. 6, the curing of the resin starts at $113.2^{\circ} \mathrm{C}$ and the endothermic peak of the Sn-Bi eutectic point is observed at $141.1^{\circ} \mathrm{C}$. The endothermic peak of Sn-Bi during the second heating is observed at $145.6{ }^{\circ} \mathrm{C}$. It is almost identical to the $5 \mu \mathrm{m}$ (a)

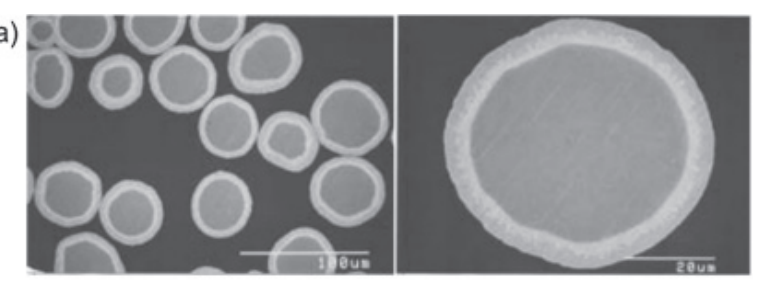

(b)

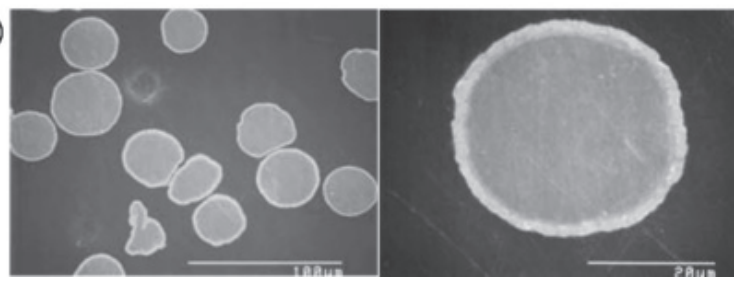

Fig. 5 Cross sectioning of $\mathrm{Cu}$ particles coated with $\mathrm{Sn}-\mathrm{Bi}$ alloy. (a) $\mathrm{Cu}$ particles of coating thickness with $5 \mu \mathrm{m}$. (b) Cu particle of coating thickness with $2 \mu \mathrm{m}$.

Sn-Bi coating one. The re-melting behavior of this solder paste shows that, at the end of the second heating, the $5 \mu \mathrm{m}$ Sn-Bi layer alloying is not completed which confirms the residual influence of Sn-Bi. These dynamic DSC results shows that similarly to the section 3.3, the best $\mathrm{Sn}-\mathrm{Bi}$ coating thickness to avoid a remelting is around 1 to $2 \mu \mathrm{m}$.

To accelerate the alloying of the $\mathrm{Cu}$ and $\mathrm{Sn}$ when the SnBi coating is thick, increasing the curing temperature and prolonging the curing time could be a solution. However, this action would affect the heat curing characteristics of the bonding sheet and the heat resistance property of the circuit board material.

Furthermore, it is not possible to simply apply a bonding condition over a long period of time at a high temperature. Therefore, it is necessary to be sure that $\mathrm{Cu}$ and the alloy are formed at the first curing process of the paste. When designing the composition, a method in which the $\mathrm{Sn}$ and Bi would be directly coated to the spherical copper powder having a relatively large particle size was adopted. With this method, the $\mathrm{Sn}-\mathrm{Bi}$ alloying can be directly in contact with the $\mathrm{Cu}$ from the beginning. By appropriately controlling the coating thickness of $\mathrm{Sn}-\mathrm{Bi}$ with this method, the $\mathrm{Sn}-\mathrm{Bi}$ alloy deposit is likely to remain after the first alloying with the $\mathrm{Cu}$ core is reduced to a minimum.

The metal particles of the conductive paste are generally mainly composed of $\mathrm{Cu}$ or $\mathrm{Ag}$ of $10 \mu \mathrm{m}$ or less (in some cases, $5 \mu \mathrm{m}$ or less), and a mix of melting point adjusting metals such as $\mathrm{Sn}$ or Bi. When such a kind of paste formulate the alloy, a part of $\mathrm{Sn}$ and $\mathrm{Bi}$ is not in contact with the $\mathrm{Cu}$ particles, and the problem of re-melting still remains after high temperature exposure. The results shows that a reliable alloying is possible with a 1 to $2 \mu \mathrm{m} \mathrm{Sn-Bi} \mathrm{coating} \mathrm{on} \mathrm{Cu}$ particles. Furthermore, the endothermic peak disappear after the first heating, depending on 


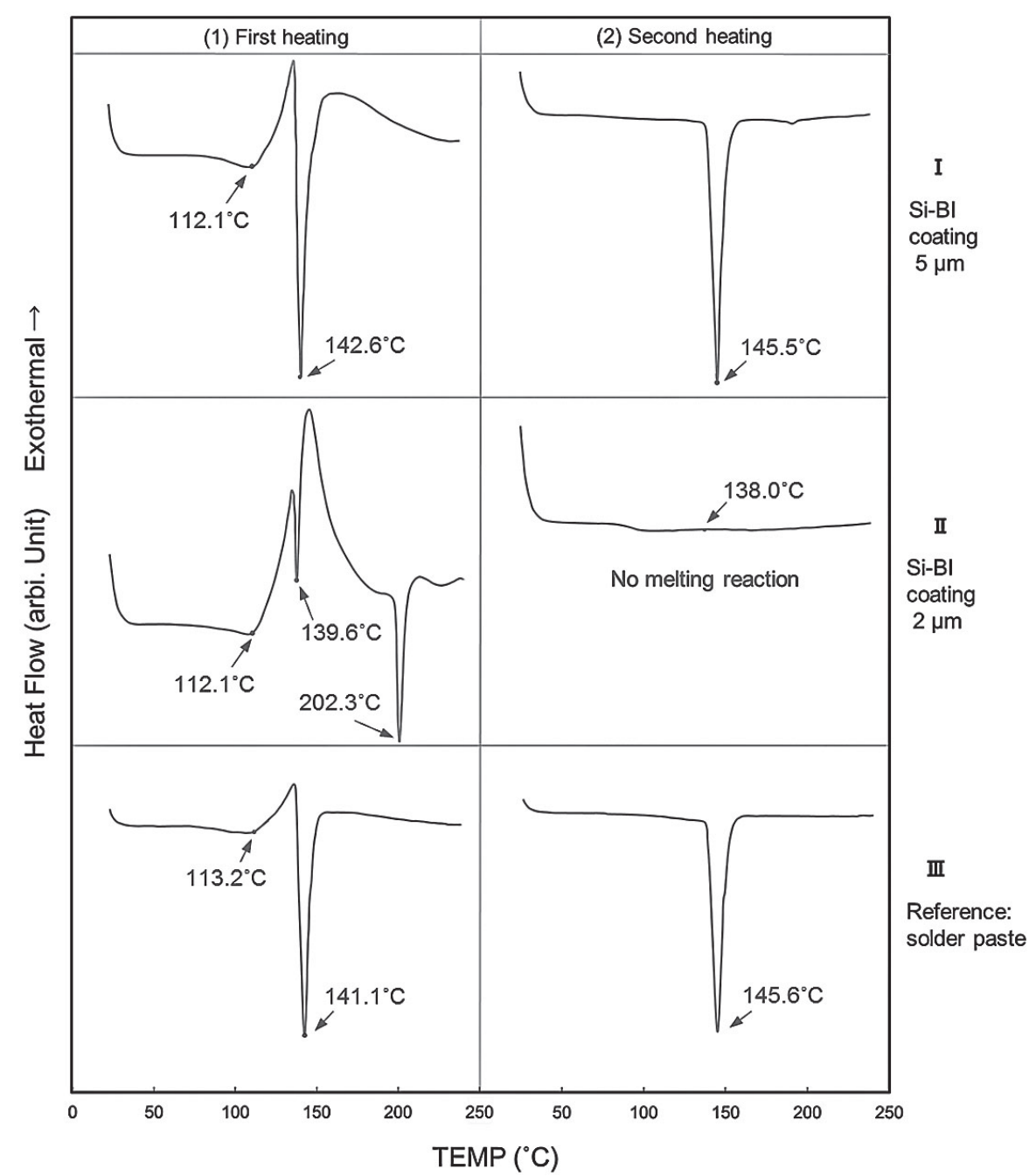

Fig. 6 Measurement result of dynamic DSC. I : Case as heating of $5 \mu \mathrm{m} \mathrm{Sn-Bi.} \mathrm{II} \mathrm{:} \mathrm{Case} \mathrm{heating} \mathrm{of}$ $2 \mu \mathrm{m}$ Sn-Bi. III : Case as heating of reference solder paste.

increasing the efficiency of $\mathrm{Cu}-\mathrm{Sn}$ alloying. Therefore, this paste makes it possible to solve any concerns about re-melting such as component mounting after the paste bonding.

\section{Conclusions}

In this study, the thermal properties of a $\mathrm{Cu}$ filler alloying to create a melting point change type conductive paste were found. The results are summarized below:

During the elemental mapping analysis, some Sn-Bi coating residue were founded on the $\mathrm{Cu}$ surface which made it evident that an appropriate thickness of $\mathrm{Sn}-\mathrm{Bi}$ coating is essential to complete the alloying on time. The observing result of these dynamic DSC showed that even under a repeated hightemperature environment, an alloying layer of about 1 to $2 \mu \mathrm{m}$ thickness would not re-melt.

This alloying can ensure the stabilization of the interconnection between circuit boards even after a few high-temperature exposure.

\section{References}

1) S. K. Kang, S. Buchwalter and C. Tsang: Journal of Electronic Materials, 29-10 (2000) 1273-1283.

2) S. K. Kang and S. Puruchothaman: Proc. 48th Electronic Components and Technology Conference, 1998, p1031-1035.

3) S. K. Kang, S. L. Buchwalter, N. C. LaBianca, J. Gelorme, S. Purushothaman, K. Papathomas and M. Poliks: IEEE Transaction on Components and Packaging Technologies, 24-3 (2001) 431-435.

4) Y. Kitamura, S. Watanabe and Y. Kawanobe: Journal of DENKISEIKO, 72-4 (2001) 239-245.

5) M. Inoue and Y. Sakaniwa: Proc. IEEE 66th Electronic Components and Technology Conference, 2016, p2068-2074.

6) A. Ono and N. Kondo: Journal of the Japan Institute of Electronics Packaging, 7-6 (2004) 482-486.

7) Y.-S. Eom, H.-S. Lee, H.-C. Bea, K.-S. Choi and J.-H. Lee: Proc. European Microelectronics Packaging Conference (EMPC), 2015, p1-5

8) D. Lu, Q. K. Tong and C. P. Wong: Proc. International Symposium on Advanced Packaging Materials Proceedings, 1999, p2-10. 
9) H. Nishikawa: Journal of the Japan Welding Society, 81-1 (2012) 4557.

10) H. Nishikawa: Journal of Smart Processing, 1-3 (2012) 138-142.

11) Y. Mizuno, K. Terashita, and K. Miyanami: Journal of the Advanced Powder Technology, 30-6 (1993) 435-441.

12) S. Kohinata: Journal of the Japan Institute of Electronics Packaging, 9-6 (2006) 495-505.

13) S. Kohinata: Journal of the Japan Institute of Electronics Packaging, 10-1 (2007) 88-98.

14) A. Hirose: Journal of the Japan Welding Society, 80-8 (2011) 702708.

15) Y. -D. Chiu and W. -P. Dow: Journal of Electrochem. Soc., 160-12 (2013) D3021-3027.

16) Echigo and M. Hirai: Panasonic Technical Journal, 55-2 (2009) 119123.

17) Y. Fukuoka, K. Sasaoka and T. Motomura: Journal of the Japan Institute of Electronics Packaging, 11-4 (2008) 260-270.

18) D. Andoh: Journal of the Japan Institute of Electronics Packaging, 3-7 (2000) 557-562.

19) H. Kamiya, T. Miyake, H, Kobayashi and K. Kondo: DENSO Technical Review, 11-2 (2006) 103-107.

20) Y. Yazaki, T. Yokochi, R. Kataoka, K. Suzuki and K. Kondo: DENSO Technical Review, 10-2 (2005) 85-89
21) M. Okamoto, A. Ito, K. Inoue. T. Kido, S. Takenaka and N. Ozawa: Proc. 19th. The Japan Institute of Electronics Packaging Annual Meeting, 2005, p17B-09.

22) Y. Oka, T. Kasuga, H. Tomioka, S. Uehara, J. J. Park, N. Uenishi and Y. Okuda: SEI Technical Review, 75 (2012) 106-109.

23) J. M. Lauffer and K. Knadle: Proc. IMAPS, 2014, p141-147.

24) R. N. Das, F. D. Egitto, J. M. Lauffer, D. Poliks and V. R. Markovich: Proc. IEEE 59th Electronic Components and Technology Conference, 2009, p180-187.

25) K. Kakizawa: Proc. 25th. The Japan Institute of Electronics Packaging, 2011, p10D-08.

26) M. Yonezumi, S. Okumoto, Y. Fukuhara and H. Hino: Panasonic Technical Journal, 59-1 (2013) 72-76.

27) K. Suganuma, K. Niihara, T. Moritho and Y. Nakamura: The journal of Japan Institute for Interconnecting and Packaging Electronic Circuits, 12-6 (1997) 406-412.

28) K. Suganuma: The journal of Japan Institute for Interconnecting and Packaging Electronic Circuits, 12-2 (1997) 83-89.

\section{Mail Address}

Kaoru SUGIMOTO sugimoto.kao@jp.fujitsu.com 